\title{
Penerapan QR Code pada Presensi Seminar Kerja Praktek Teknik Informatika Unwahas Berbasis Android
}

\author{
Nugroho Eko Budiyanto ${ }^{1 *}$, Riza Sultonuddin ${ }^{2}$ \\ ${ }^{1,2}$ Jurusan TEKNIK INFORMATIKA, Fakultas TEKNIK, Universitas Wahid Hasyim \\ Jl. Menoreh Tengah X/22, Sampangan, Semarang 50236. \\ "Email: nugroho.eb@gmail.com
}

\begin{abstract}
Abstrak
Kerja Praktek merupakan salah satu mata kuliah yang harus ditempuh mahasiswa pada Teknik Informatika Unwahas. Mahasiswa dituntut untuk melaksanak kerja praktek pada salah satu perusahaan dan wajib membuat laporan yang hasil laporan tersebut harus dipresentasikan dalam sebuah seminar. Adanya beberapa syarat yang harus dipenuhi mahasiswa agar dapat mendaftar seminar kerja praktek salah satunya mahasiswa harus menghadiri minimal 10 kali seminar kerja praktek untuk acuan dan referensi ketika akan membuat laporan kerja praktek. Untuk presensi tersebut masih dilakukan secara sederhana menggunakan kertas yang ditulis lalu dosen memberikan tandatangannya sebagai tanda kehadiran. Haltersebut seringkali membuat mahasiswa kesulitan apabila kertasnya hilang dan harus mengulang kehadiran kembali. Sistem yang dikembangkan menggunakan metode waterfall yang memiliki tahapan pengumpulan data, analisis, perancangan, pengkodean, pengujian dan pemeliharaan. Penelitian ini menghasilkan berupa penerapan Qr Code pada presensi seminar kerja praktek Teknik Informatika Unwahas Berbasis Android guna memudahkan mahasiswa untuk presensi pada seminar kerja praktek yang bisa diakses dengan telepon seluler (Smartphone) masing-masing.
\end{abstract}

Kata kunci: Android, Presensi, QR-Code, Waterfall

\section{PENDAHULUAN}

\subsection{Latar belakang masalah}

Seiring berjalannya waktu perkembangan Teknologi Informasi, khususnya internet dan teknologi mobile memungkinkan pengembangan untuk meningkatkan layanan informasi dalam suatu instusi pendidikan. Pemanfaatan teknologi informasi dengan jaringan internet telah memberikan dampak positif terhadap semua bidang, di bidang ini salah satunya pendidikan. Pemanfaatan teknologi informasi untuk bidang pendidikan sangat membantu untuk meningkatkan pelayanan mutu Pendidikan, tidak menutup kemungkinan bahwa telepon seluler (Smartphone) dapat dimanfaatkan sistem presensi untuk Perguruan Tinggi. Sebuah ponsel yang di dalamnya memiliki sistem operasi ciri-ciri utama mampu mengakses internet smartphone. Smartphone merupakan expansi teknologi dari ponsel yang menyajikan tampilan menarik semacam halnya pada komputer. Salah satu fitur yang menarik dari smartphone adalah kemampuannya dalam mengambil, menyimpan, serta menampilkan gambar dengan format JPEG/PNG karena kebanyakan handphone memiliki kamera. Saat ini penggunaan dalam barcode sudah tidak asing lagi dalam dunia. Hal ini dapat mempermudah para pelaku industri dalam menjaga inventori mereka yang meliki, sebab barcode ini dapat menyimpan seperti nomor identitas, kode produksi dan lain- lain sehingga sistem yang terdapat pada komputer informasinya bisa dikenal oleh barcode dengan mudah. Dengan adanya perkembangan teknologi yang sangat cepat, pemakaian barcode mulai jarang digunakan dan dirubah dengan QR Code. (labolo, 2019)

Seminar Kerja Praktek merupakan salah satu mata kuliah yang harus ditempuh mahasiswa pada Teknik Informatika Unwahas. Mahasiswa dituntut untuk melaksanakan kerja praktek pada salah satu perusahaan dan wajib membuat laporan yang hasil laporan tersebut harus dipresentasikan dalam sebuah seminar. Adanya beberapa syarat yang harus dipenuhi mahasiswa agar dapat mendaftar seminar kerja 
praktek salah satunya mahasiswa harus menghadiri minimal 10 kali seminar kerja praktek untuk acuan dan referensi ketika akan membuat laporan kerja praktek. Untuk presensi tersebut masih dilakukan secara sederhana menggunakan kertas yang ditulis lalu dosen memberikan tandatangannya sebagai persetujuan tanda kehadiran. Hal tersebut seringkali membuat mahasiswa kesulitan apabila ketika kertasnya hilang dan harus mengulang kehadiran kembali.

Berdasarkan kondisi tersebut dibutuhkan sebuah sistem presensi yang dapat memberikan kemudahan mahasiswa untuk presensi kehadiran pada seminar kerja praktek berbasis android yang bisa diakses dengan telepon seluler (Smartphone) masing-masing.

\subsection{Rumusan Masalah}

Berdasarkan uraian yang terdapat pada latar belakang sub bab berikutnya, maka dapat dirumuskan masalah yaitu bagaimana merancang bangun sebuah sistem aplikasi presensi seminar kerja praktek Teknik Informatika Unwahas menggunakan teknologi QR Code berbasis android?

\subsection{Batasan Masalah}

Dalam penelitian ini, penulis membatasi masalah sebagai berikut:

1. Penelitian ini difokuskan pada presensi seminar kerja praktek teknik informatika unwahas.

Aplikasi ini terbatas di android untuk presensi seminar kerja praktek teknik informatika unwahas

\section{TINJAUAN PUSTAKA}

Dalam penyusunan penelitian ini, penulis sedikit terinspirasi dan sebagai literatur dari penelitian-penelitian yang sudah ada sesui dengan latar belakang masalah. Adapun penelitian yang berkaitan antara lain yaitu:

1. Implementasi $Q R$ Code Untuk Absensi Perkuliahan Mahasiswa Berbasis Paperless Office. (labolo, 2019) Menemukan masalah pokok yang menjadi pembahasan yaitu penerapan sistem presensi yang sedang dan telah berjalan saat ini di STMIK Ichsan Gorontalo masih menggunakan banyak kertas kemungkinan bisa tercecer atau hilang. Aplikasi ini memakai metode
Penelitian dan Pengembangan. Maka penelitian ini menghasilkan sistem presensi berbasis mobile yang mendukung paperless office.

2. Pemanfaatan $Q R$ Code Dalam Memudahkan Proses Absensi Siswa Berbasis Aplikasi Mobile. (Pulungan \& Saleh, 2019) Menemukan masalah pokok yang terjadi pembahasan yaitu pada sistem absensi siswa masih menggunakan cara manual, sehingga kurang efisien dalam penggunaan karena informasi tentang kehadirannya bisa saja ada kecurangan baik dari pihak murid ataupun guru yang salah dalam menandai kehadiran siswa. Aplikasi ini memakai metode diagram fishbone. Maka dari penelitian ini menghasilkan sebuah sistem absensi dengan menggunakan smartphone android dan juga QR Code yang lebih baik dan mudah diimplementasikan pada perangkat mobile.

3. Sistem Informasi Buku Tamu Menggunakan Qr code Berbasis Web Pada PT Petrokimia Gresik. (Mubarok \& Chotijah, 2021) Menemukan masalah pokok yang menjadi pembahasan yaitu dalam penerimaan tamu hingga sekarang Petrokimia melakukannya dengan menggunakan buku tamu manual yakni dengan tulisan tangan. dengan proses penerimaan tamu seperti ini dikawatirkan para karyawan Petrokimia akan berkontak fisik dengan tamu baik secara langsung maupun dengan perantara seperti pulpen, kertas, dll. Aplikasi ini memakai metode Waterfall. Maka dari penelitian ini menghasilkan sebuah Sistem Informasi Buku Tamu Menggunakan $Q R$ code Berbasis Web Pada PT Petrokimia Gresik, untuk menangani kontak fisik secara langsung antar pegawai Petrokimia Gresik dengan tamu yang berkunjung.

Perbedaan penelitian yang dilakukan dengan penulis yaitu pada sistem yang hendak dirancang memiliki dua user yaitu admin dan mahasiswa. semua informasi akan diupload didalam sistem website tersebut. sehingga memudahkan mahasiswa dapat informasi dan aplikasi presensi untuk menscan $Q R$ Code yang sudah di buat oleh admin. 


\subsection{Landasan Teori \\ 2.1.1. Presensi}

Presensi adalah mengumpulkan data kehadiran, dari bagian terkait dalam aktifitas suatu instansi, atau institusi berisikan data kehadiran yang tersusun sedemikian rupa sehingga mudah untuk dicari dan dipergunakan sewaktu-waktu oleh yang berkepentingan. (Purwanto, 2014)

\subsubsection{QR Code}

Kode QR atau biasa dikenal dengan istilah $Q R$ Code adalah bentuk evolusi kode batang dari satu dimensi menjadi dua dimensi. Pengguna Kode QR di Jepang yang sebelumnya berupa kode batang umumnya sudah sangat lazim oleh sebab itu data yang diperlukan lebih besar untuk membaca kode huruf Kanji sebagai informasi. Sehingga Jepang menerapkan standarisasi Internasional berupa ISO/IEC18004 dan JIS-X-0510 dan telah dipakai secara luas melalui smartphone di Jepang. (Habibi, Fakhri, \& Damayanti, 2020).

\subsubsection{Android}

Android merupakan sistem operasi yang banyak digunakan pada perangkat bergerak yang dewasa ini sangat terkenal dan populer digunakan pada ponsel cerdas. Android juga merupakan platform pemrograman yang disempurnakan oleh Google untuk ponsel cerdas dan perangkat seluler lainnya, misalnya tablet. Android bisa berjalan di beberapa macam perangkat yang dikembangkan oleh banyak vendor ponsel cerdas yang berbeda. Android menambahkan paket pengembangan perangkat lunak untuk penulisan kode asli dan perakitan modul perangkat lunak dalam membuat aplikasi bagi pengembang Android. (Herlinah \& Musliadi, 2019)

\subsubsection{Android Studio}

Android Studio merupakan lingkungan pengembangan perangkat lunak terpadu Integrated Development Environment (IDE) untuk pengembangan aplikasi android, berdasarkan IntelliJ IDEA. Selain merupakan editor kode IntelliJ dan alat pengembang yang bermanfaat, Android Studio juga menawarkan banyak fitur untuk meningkatkan kreativitas Anda saat membuat aplikasi Android, (Herlinah \& Musliadi, 2019) misalnya:

1. Sistem versi berbasis Gradle yang fleksibel.

2. Emulator yang cepat dan kaya fitur.
3. Lingkungan yang bekerjasama untuk peningkatan bagi semua perangkat android.

4. Instant Run untuk mendorong perubahan kode tanpa harus membuat APK baru.

5. Kode Template dan Integrasi GitHub untuk membuat fitur aplikasi yang sama dan menginpor kode contoh.

6. Memiliki alat pemeriksaan dan rangka kerja yang ekstensif.

\section{Dengan beragam fitur yang diberikan} oleh Google Cloud Platform, akan memudahkan pengintegrasian Google Cloud Messaging dan App Engine.

\subsubsection{Java}

Java adalah sebuah teknologi yang diperkenalkan oleh Sun Microsysytems pada pertengahan tahun 1990. Menurut definisi Sun, Java adalah sekumpulan package untuk menjadikan dan menerapkan pada perangkat lunak untuk computer stand alone. Ketertarikan terhadap Java adalah selaku teknologi yang baik dibanding hanya sebuah bahasa pemrograman konvensional yang lain, karena java lebih lengkap. (Haqi, 2019) Teknologi Java memiliki tiga komponen penting, yaitu:

1. Java Development Kit

Java Development Kit (JDK) adalah perangkat lunak yang digunakan untuk melangsungkan proses kompilasi dari kode java ke bytecode agar mudah dimengerti dan diaplikasikan oleh Java Runtime Environtment. Java Development Kit Wajib terinstall pada computer yang akan melangsungkan proses pembuatan aplikasi berbasis java.

2. Java Runtime Environtment

Java Runtime Environtment (JRE) ialah perangkat lunak yang dipakai untuk mengimplementasikan aplikasi yang akan dibangun memakai Java. Versi JRE harus sama atau lebih tinggi dari JDK yang digunakan untuk membangun aplikasi agar aplikasi dapat berjalan sesui dengan yang diharapkan.

3. NetBeans IDE

NetBeans IDE merupakan perangkat lunak yang dipakai untuk menciptakan perangkat lunak yang lain serta dapat dipakai untuk membangun perangkat lunak berbasis Java Standard Edition, Java Enterprise Edition, Java Micro Edition, JavaFX, PHP, CfC++, Ruby, Groovy dan Python. 


\subsubsection{Use Case Diagram}

Use Case diagram merupakan pemodelan untuk alur jalannya sistem informasi yang akan dibuat. Syarat penamaan pada use case adalah pengenalan nama yang singkat dan mudah dipahami. Ada dua hal utama pada use case yaitu macam-macam aktifitas yang disebut Aktor dan use case. Aktor merupakan orang, proses atau sistem lain yang berdampingan dengan sistem informasi diluar sistem informasi itu sendiri, jadi walaupun simbol dari aktor adalah gambar orang, tapi aktor belum tentu merupakan orang. Use Case merupakan fungsionalitas yang disediakan sistem sebagai unit-unit yang saling bertukar pesan antar unit atau aktor. (Rosa, 2016)

\subsubsection{Activity Diagram}

Diagram aktivitas maupun yang disebut activity diagram menjelaskan workflow (aliran kerja) atau aktivitas kerja suatu sistem atau mengolah bisnis atau tools yang terdapat pada perangkat lunak. (Rosa, 2016)

\section{METODE PENELITIAN}

\subsection{Metode Pengumpulan Data}

Metode pengumpulan data adalah faktor terpenting yang harus dipenuhi untuk dianalisis dan diolah. Pengumpulan data bertujuan untuk memperoleh informasi yang dibutuhkan untuk menyelesaikan penelitian ini. Dalam pengumpulan data dan informasi adapun metode yang digunakan yaitu:

1. Metode Observasi

2. Metode Wawancara

3. Metode Kepustakaan

\subsection{Metode Pengembangan Sistem}

Dalam proses pengembangan sistem, penulis menerapkan metode waterfall sebagai model pendekatan pengembangan softwarenya. Metode ini adalah metode pengembangan yang sistematis dan berurutan. Dalam implementasinya metode waterfall ini memiliki beberapa tahapan secara runtut yaitu: Pengumpulan data, Analisis, Perancangan, Pengkodean, Pengujian, Pemeliharaan

\section{HASIL DAN PEMBAHASAN \\ 4.1. Perancangan Desain \\ 4.1.1 Use Case Diagram}

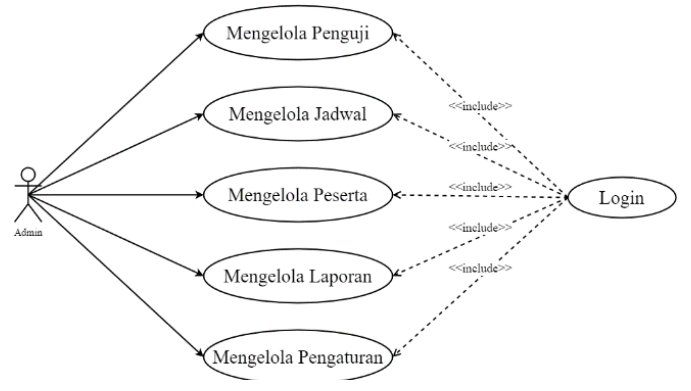

Gambar 1. Use Case Diagram Admin

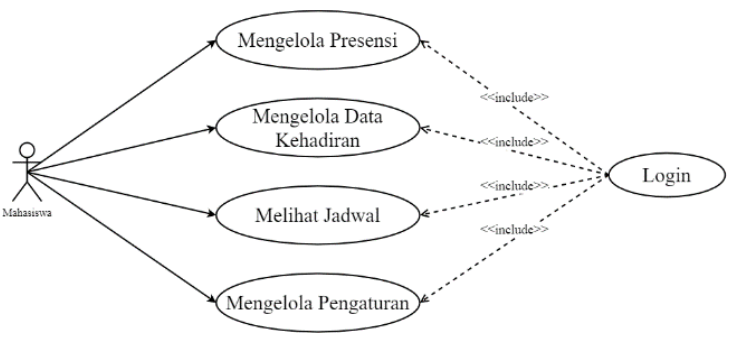

Gambar 2. Use Case Diagram Mahasiswa

\subsubsection{Activity Diagram}

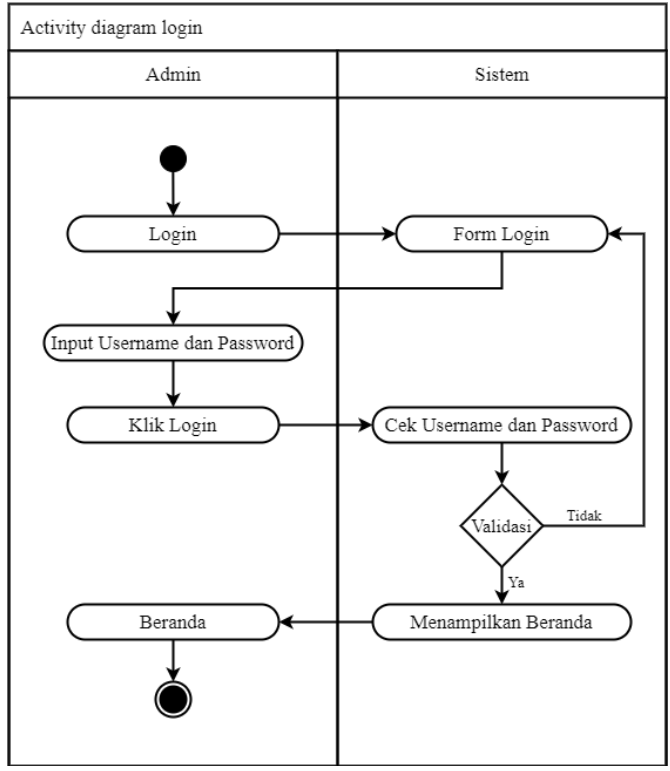

Gambar 3. Activity Diagram Login Admin 


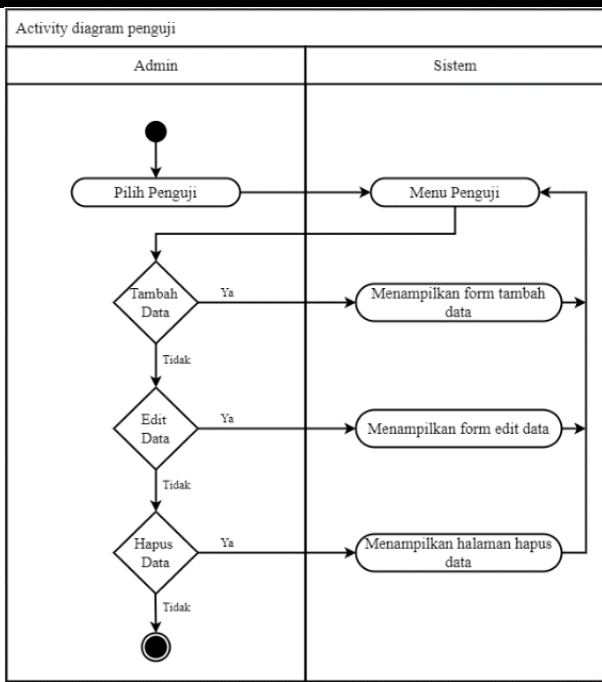

Gambar 4. Activity Diagram Penguji

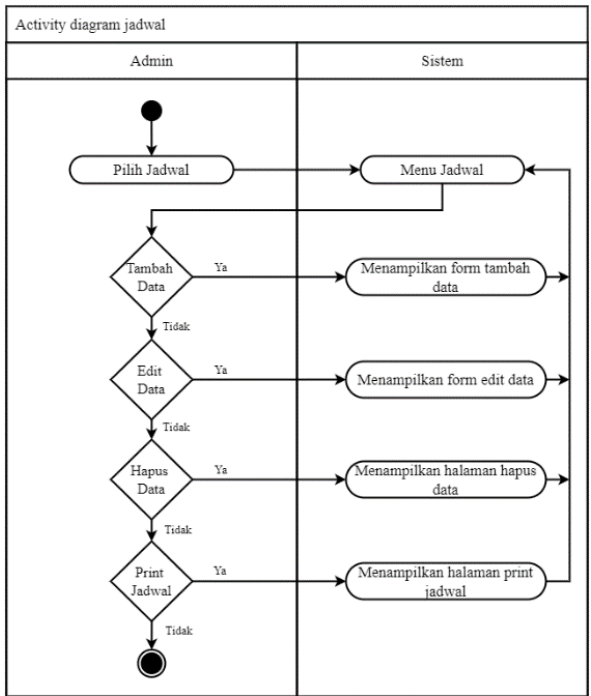

Gambar 5. Activity Diagram Jadwal

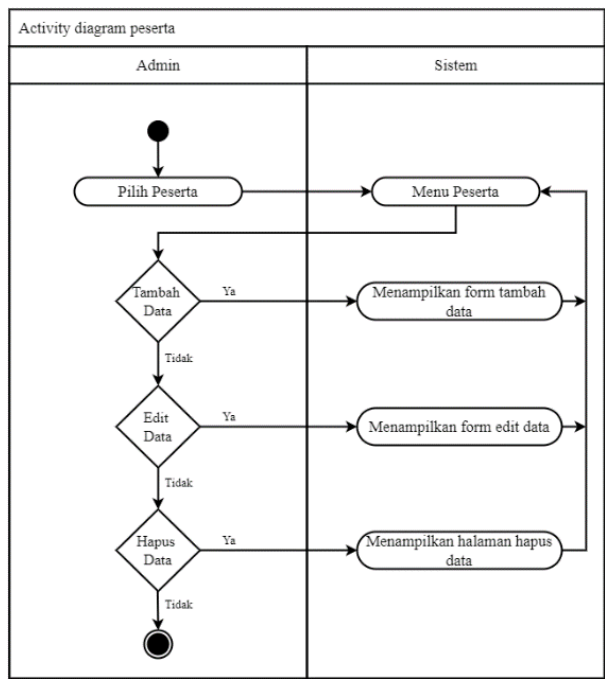

Gambar 6. Activity Diagram Peserta

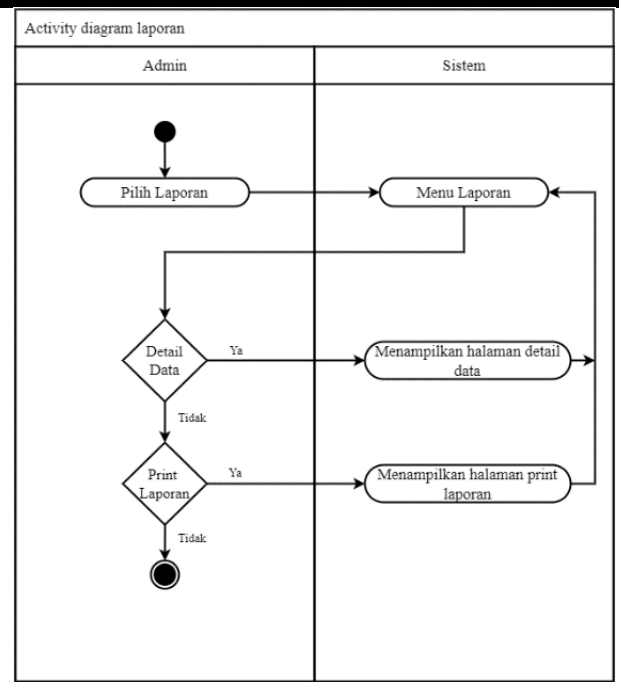

Gambar 7. Activity Diagram Laporan

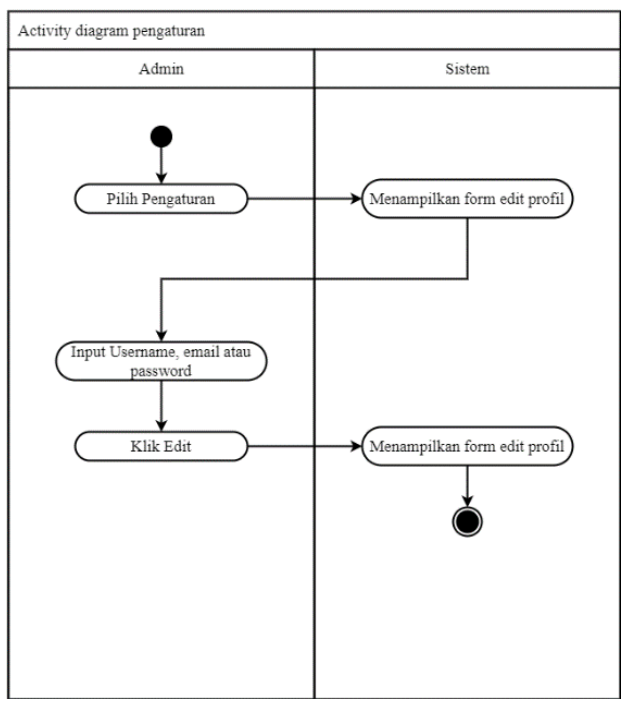

Gambar 8. Activity Diagram Pengaturan

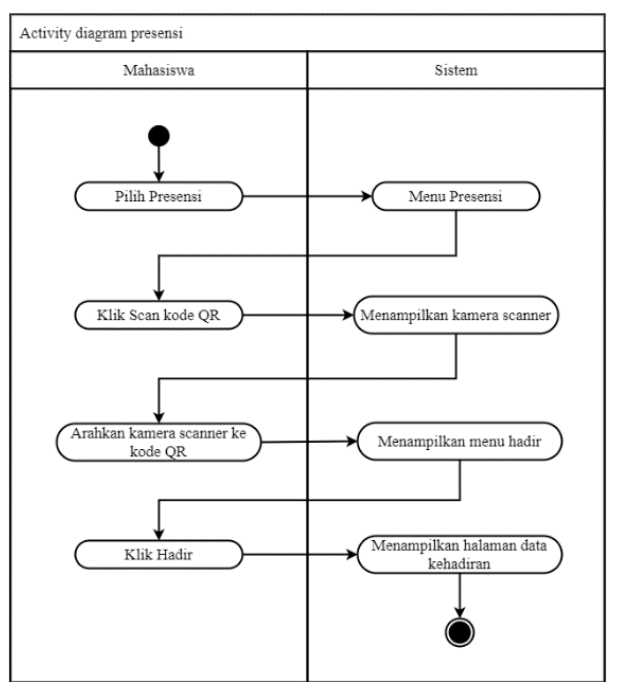

Gambar 9. Activity Diagram Presensi 


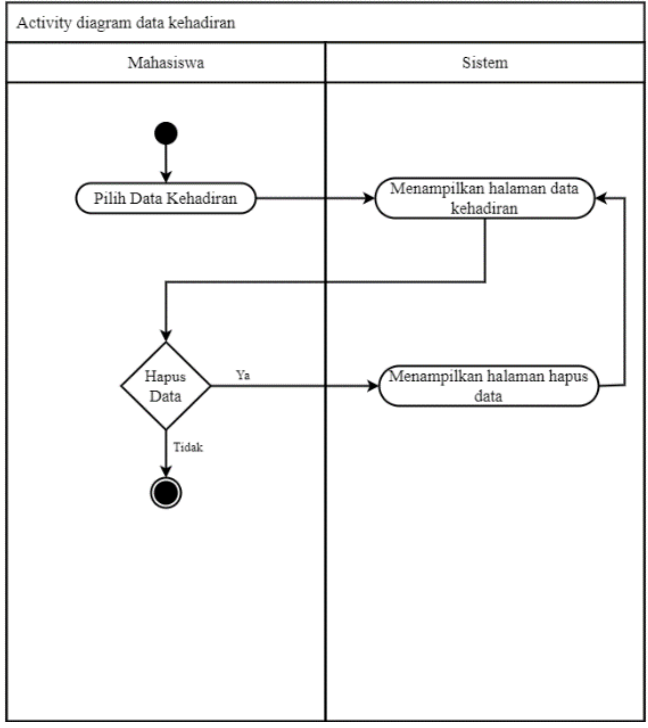

Gambar 10. Activity Diagram Data Kehadiran

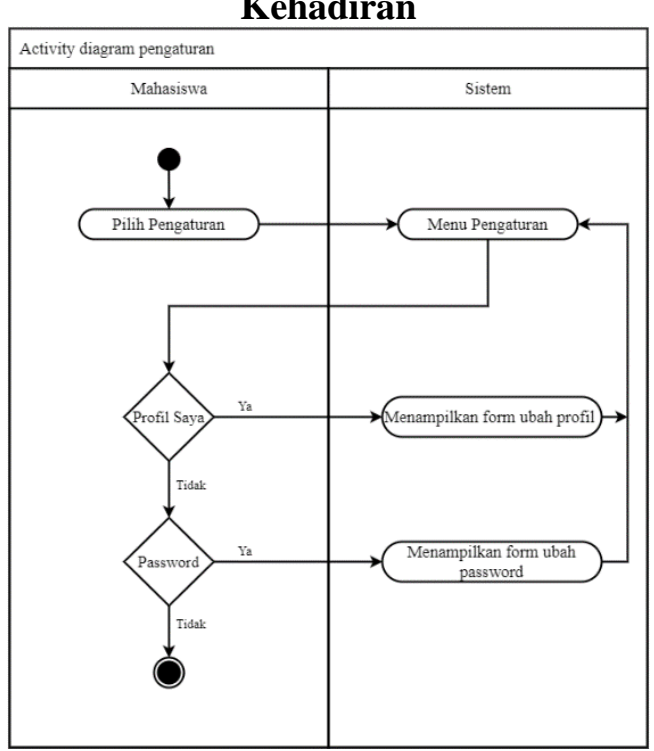

Gambar 11. Activity Diagram Pengaturan Mahasiswa

\subsection{Impementasi Desain}

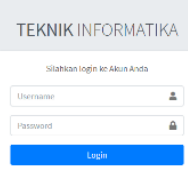

Gambar 12. Tampilan Login Admin
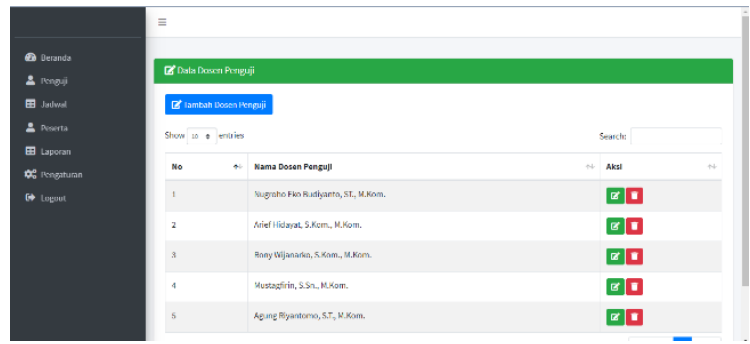

Gambar 13. Tampilan Penguji
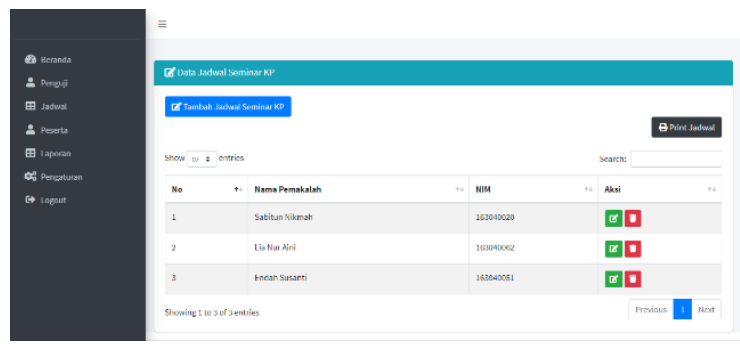

Gambar 14. Tampilan Jadwal
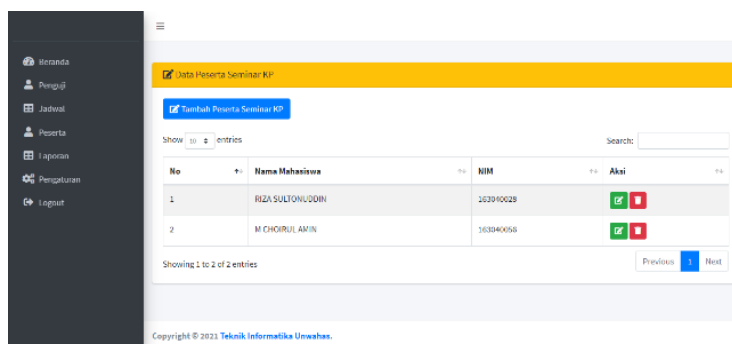

Gambar 15. Tampilan Peserta
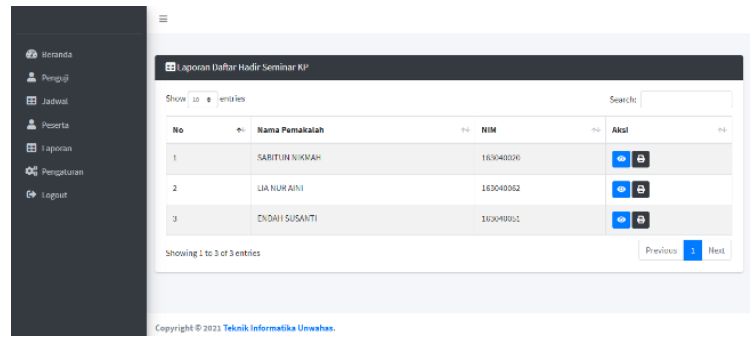

Gambar 16. Tampilan Laporan
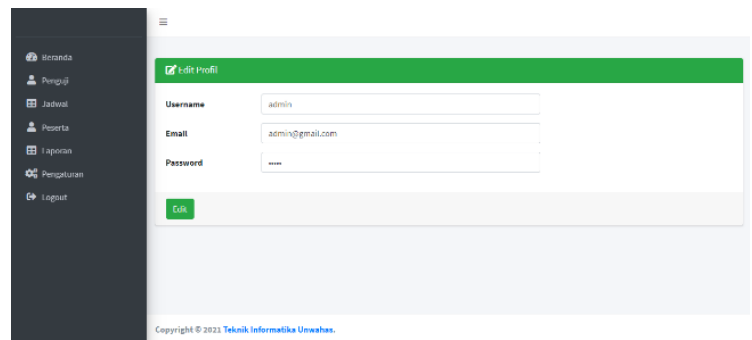

Gambar 17. Tampilan Pengaturan Admin 


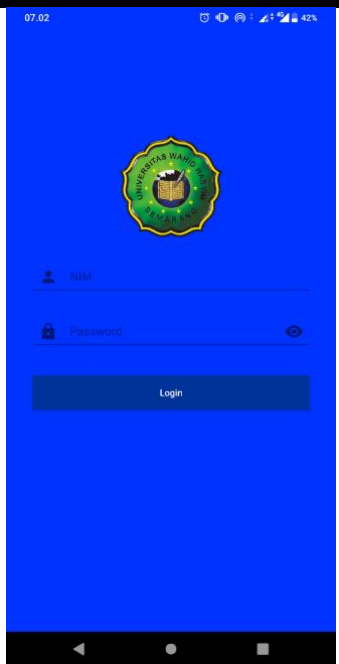

Gambar 18. Tampilan Login Mahasiswa

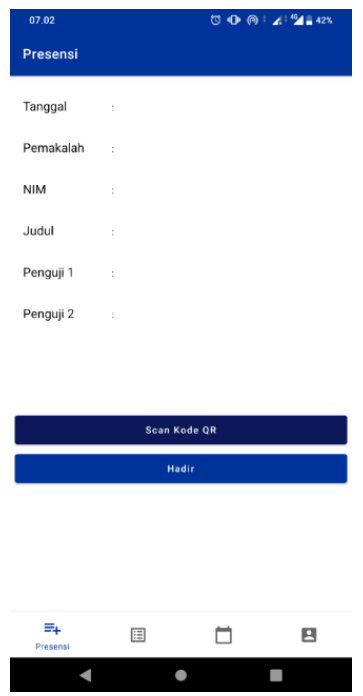

Gambar 19. Tampilan Presensi

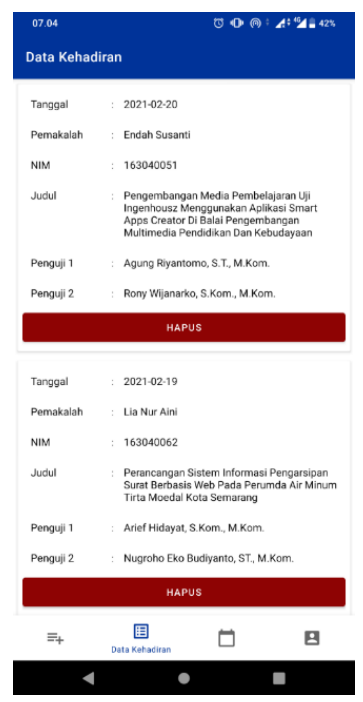

Gambar 20. Tampilan Data Kehadiran

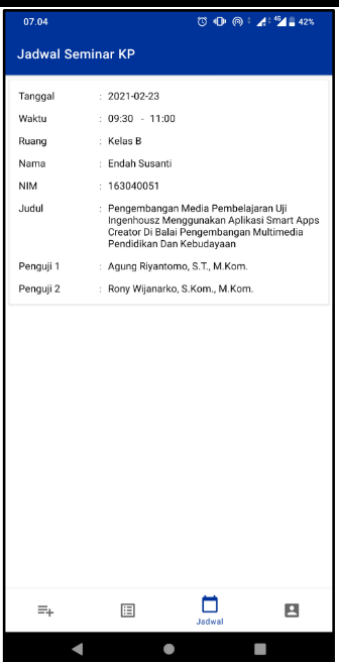

Gambar 21. Tampilan Jadwal

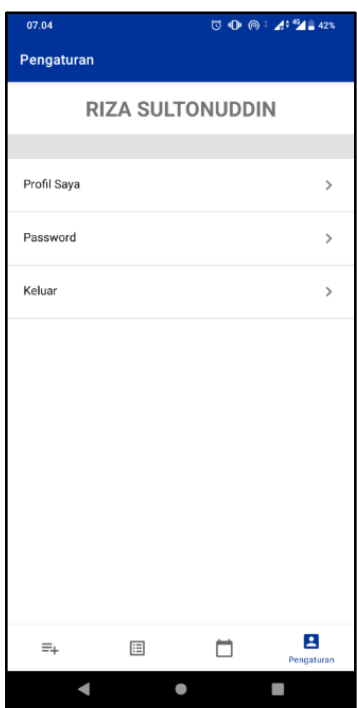

Gambar 22. Tampilan Pengaturan

\section{KESIMPULAN}

Setelah melakukan analisis, perancangan dan pembuatan Penerapan $Q R$ Code Pada Presensi Seminar Kerja Praktek Teknik Informatika Unwahas Berbasis Android dan dilakukan evaluasi hasil uji penelitian, maka kesimpulanya penulis telah berhasil membuat sebuah Penerapan QR Code Pada Presensi Berbasis Android guna memudahkan mahasiswa untuk presensi pada seminar kerja praktek yang bisa diakses melalui telepon seluler (Smartphone) masing-masing

\section{DAFTAR PUSTAKA}

Habibi, R., Fakhri, B. D., \& Damayanti, S. F. (2020). Penggunaan framework laravel untuk membuat aplikasi absensi 
terintegrasi mobile. Bandung: kreatif Industri Nusantara.

Haqi, B. (2019). Aplikasi SPK Pemilihan Dosen

Terbaik Metode Simple Additive

Weighting (SAW) Dengan Java.

Yogyakarta: Deepublish.

Herlinah, \& Musliadi. (2019). Pemrograman Aplikasi Android dengan Android Studio, Photoshop, dan Audition. Jakarta: Elex Media Komputindo.

labolo, I. (2019). Implementasi QR Code Untuk Absensi Perkuliahan Mahasiswa Berbasis Paperless Office. Jurnal Informatika UPGRIS, Volume 5, Nomor 1.

Mubarok, A. Y., \& Chotijah, U. (2021). Sistem Informasi Buku Tamu Menggunakan Qr code Berbasis Web Pada PT Petrokimia Gresik. Jurnal Ilmu Komputer dan Informatika, Volume 4, Nomor 1.

Pulungan, A., \& Saleh, A. (2019). Pemanfaatan QR Code Dalam Memudahkan Proses Absensi Siswa Berbasis Aplikasi Mobile. Jurnal Masyarakat Telematik dan Informasi, Volume 10, Nomor 1.

Purwanto, P. (2014). Evaluasi Hasil Belajar. Surakarta: Pustaka Belajar.

Rosa, A. S. (2016). Rekayasa perangkat lunak terstruktur dan berorientasi objek. Bandung: Informatika. 